\title{
Evaluating Science and Risk: Living With and Dying From Asbestos
}

\section{Linda Waldman}

\author{
1 Introduction \\ Recent Science and Technology Research has \\ examined how concepts of risk and public \\ understandings of science might be useful in non- \\ Western contexts (Fairhead and Leach 2003). \\ Pioneering work on how scientific knowledge is \\ embedded in - and interacts with - a cultural \\ context was done by Douglas and Wildavsky (1983) \\ who argued that understanding risk requires an \\ awareness of the sociocultural context alongside \\ knowledge of subjective and personal factors. \\ Wynne's interpretationist approach also focuses on \\ context and provides a means to re-examine the \\ more traditionalist, positivist survey approach to \\ public understandings of science (Wynne 1995). His \\ work draws attention to the interaction between \\ 'formal' and 'informal' forms of expertise, showing \\ how on the Cumbrian fells, sheep farmers interact \\ with physicists. He also draws attention to the \\ relational dimension of risks, asking 'how far might \\ lay people be involved in shaping scientific \\ knowledge, and thus in providing the basis for \\ alternative forms of public knowledge that reflect \\ and sustain different dominant conceptions of the \\ human, and of the social purposes of public \\ knowledge?' (Wynne 1996: 61) More recently, Furedi \\ has reinforced the centrality of context in his \\ argument that 'fears about the future are linked to \\ anxieties about problems today. And if the future is \\ feared, then reaction to risk is more likely to \\ emphasize the probability of adverse outcomes' \\ (Furedi 2002: 18). \\ In contrast to the science and technology debate, \\ much of the literature on participation and \\ citizenship has focused on developing contexts and \\ on enhancing democracy and governance, (Cornwall \\ 2004; Gaventa 2002). As Leach et al. (2002: 41) \\ argue, there is a need to 'explore the cross-context \\ 'translateability' of theories and debates and the \\ possibilities of cross-learning'. In exploring
}

contrasting conceptualisations of harm, this article argues that scientific understandings of risk and a 'public understanding' of risk are not mutually exclusive. Indeed, it is specifically through opportunities for participation and collective action around scientific issues that both scientific and lay understandings of risk are broadened. Using asbestos exposure and the risk of contracting asbestos-related disease (ARDs) in a non-western context as the site of investigation, this article argues that evaluations of risk are not always negative; that risk is not always linked to probability, and is not always forwardlooking to the future. It furthermore shows how, contrary to many studies of public understandings of science which 'keeps science and non-science distinct' (Michael 2002: 359), notions of science, risk and bodily harm shaped during processes of participation and political decision-making, are interwoven with everyday knowledge and experiences.

This article examines two, apparently contrasting interpretations of asbestos risk and harm in the Northern Cape, South Africa; namely a medical, scientific discourse about the probability of risk and an emic ${ }^{2}$ viewpoint about bodies, relationships and emotions. Although they appear as separate, unrelated interpretations, the cultural embeddedness of 'the public' and the fact that society is 'mutually implicated in science' (Michael 2002: 374) is taken as a starting point for the analysis. This mutual implication is seen to take place through public participation in policy forums and through local communities' engagement with science in hospitals, in relation to funerals, when removing exposed asbestos and so forth.

Richards has argued that participation can be understood in two forms: deliberative participation and performative participation (this IDS Bulletin). Focusing on the latter, in which participation is seen 
to include action, ritual, belief and performance, Richards argues that the participatory event has the capacity to 'generate excitement relevant to the fixing of collective representations' and, in so doing, produce new forms of action, belief and commitment (2006: 3). In an examination of agricultural innovation as performance, Richards argues that 'interaction between people with different kinds of knowledge and different areas of experience can be a necessary stimulus' (1989: 46). It is through the 'doing' of technology, through action, that material outcomes and social values are achieved (this IDS Bulletin). Drawing on this knowledge-as-action approach, this article suggests that the different ways of conceptualising harm and risk - local cultural understandings and scientific approaches - interweave and support each other at times, but can also present contradictory and divergent interpretations of danger. The article further argues that understanding scientific knowledge is linked to activities and is therefore skillbased. As demonstrated in the material below, when agencies and local communities take concerted action, a broadened understanding of risk is established, which draws on both scientific understandings and community perspectives of risk.

The article focuses on the mining town of Prieska, but also draws from other rural Northern Cape towns, such as Griquatown, Niekerkshoop, Koegas, Kuruman and Marydale. ${ }^{3}$ Scientific data from academic publications, government documentary sources and records from government and community meetings on asbestos as well as interviews with medical specialists, community organisers and government officials have been complemented by a long period of qualitative participant observation conducted during 1997 and 1998. In 1999, 2003 and 2006, shorter, follow-up visits focused on official attempts to deal with asbestos diseases and people's participation in these processes. Most of this research was conducted in Afrikaans, which is the lingua franca in the Northern Cape.

\section{The history and science of asbestos}

South Africa witnessed a century of asbestos mining, from 1893 until 1989. Despite evidence of the dangers, mining companies emphasised factory safety and new technologies of dust control while simultaneously disguising employees' ill-health and downplaying the scientific evidence of ARDs
(McCulloch 2002). As Myers has shown, the standards used in South Africa to define 'safe levels' were not based on debilitating ARDs such as mesothelioma, but rather on benign pleural disorders; thus justifying extensive exposure to asbestos fibres (Myers 1981: 231). The collusion between the South African government and asbestos mining companies was further enforced during the Second World War, when companies were granted reprieves from state legislation (Braun et al. 2003: 194). In addition, asbestos companies described the extraction process as 'not strictly mining', thus evading the mining legislation (despite opposition from the Departments of Native Affairs and Health). This, coupled with financial support to and control over medical research, enabled mining companies to ignore the dangers of asbestos and to oversee an enormously profitable extraction process (Ehrlich et al. 1994; McCulloch, 2002, 2005).

Thus, while industrialised countries experienced public contestation over the hazards and uncertainties associated with technological processes and scientific developments (Castleman 2001), asbestos mining flourished in South Africa (McCulloch 2005). ${ }^{4}$ Asbestos mining was primarily open-caste mining in which the earth was dislodged through dynamite. Women processed the asbestos by hand, often sitting in the open, cobbing asbestos, while breast-feeding or while children played around them. Asbestos workers and their families were thus in daily contact with the hazardous material while the asbestos industry, supported by senior personnel in the Department of Mines, argued that asbestos was not carcinogenic. This alliance between industry and government labelled growing international evidence of asbestos hazards as 'wrong and prejudiced publicity' and as 'propaganda' (McCulloch 2005: 8)

In the lead-up to the democratic elections of 1994 and the end of apartheid, a concerted effort to deal with asbestos-related problems emerged. South African civil society organisations and rural communities questioned the dangers of asbestos exposure (Felix 1991). Academics focused on a range of issues, such as historical processes detailing the power of mining companies (Myers 1981; McCulloch 2002) and health, compensation and rehabilitation (Ehrlich et al. 1994; Hessel and Sluis-Cremer 1989; Randeree 1998), while lawyers campaigned for social justice and better corporate responsibility (Meeran 
2003; Ward 2002; Newell 2001; Coombs 2002). The new South African government supported these activities and undertook to address environmental rehabilitation and the provision of health facilities, although financial constraints have made these difficult undertakings (discussed further below).

Today, South Africans have little doubt about the dangers of asbestos and all asbestos mining has been banned, while the use of manufactured asbestos products is being phased out. ${ }^{5}$ Because the mines have all been closed, and because many of the companies were not South African, it has been very difficult to address issues of corporate social responsibility and hold these private companies accountable. Although Cape Plc - a company which mined in Prieska and ran a mill in the centre of the town - was forced to pay compensation to 7,500 former employees with asbestos-related diseases in 2003; it was a long, arduous and difficult experience, which lasted many years (Waldman 2005). Although the mines have all been closed, it is now widely accepted that exposure to asbestos fibre can result in ARDs. Certain towns and rural areas have been acknowledged as polluted and people from a variety of backgrounds have come together to seek solutions.

\section{The Northern Cape: asbestos pollution and community participation}

The rural town of Prieska has featured prominently in the media on asbestos pollution. The close proximity of asbestos mines, dumps and the former milling of asbestos in the centre of the town has heightened the likelihood of people contracting ARDs. ${ }^{6}$ In 1985, towns such as Kuruman,

Postmusburg, Prieska and Vryburg were declared 'dust control areas'. Although this meant that the asbestos waste dumps were to be covered with soi (Distrikstrekordboek 1978), little was done to redress the situation and to protect people from exposure to waste asbestos. Only after a decade of the Concerned People Against Asbestos's (CPAA) concerted activities to address the health, environmental and occupational spread of asbestos issues, and after the 1994 transition to a democratic government, was there official recognition that asbestos pollution was a provincial concern. The African National Congress (ANC)-led government also sought to encourage local level community participation through the Municipal Structures Act, through Local Government Councils, through the 'constitutional requirements of transparent, accountable, democratic practices in all areas of governance' and through communities' rights to participation in local development (Williams 2004: 20).

Stakeholders within the Northern Cape created a multi-stakeholder Asbestos Forum, comprising of various government departments ${ }^{7}$ to ensure joint consultative decision-making, rather than a fragmented approach to rehabilitation (Minutes of the Asbestos Forum Meeting, 6 November 1997). Community representatives and the CPAA were critically involved in this forum, participating in decision-making and supporting the political process. The Asbestos Forum Meetings thus created an 'invited space' characterised by regularity, deliberation and participation (Cornwall 2004). In so doing, community representatives 'exercised voice' and were expected to 'become empowered' through the process of participation (cf. Gaventa 2002). However, as Leach et al. (2002: 40) point out, community participation is particularly challenging when dealing with scientific and technological issues because, on the one hand, 'highly specialised professionalised knowledge and expertise' may restrict participation, while recent scientific controversies have, on the other hand, 'created new demands and opportunities for concerted citizen engagement in decision making'.

In conjunction with concerted efforts to improve health facilities, the multi-stakeholder forum focused on three main areas of intervention: medical screening, rehabilitation of mining areas and community development (discussed in more detail later). In contrast to the Western public understanding of science literature, which sees lay people's scientific knowledge as inadequate and thus limiting their citizen involvement (Michael 2002: $359)^{8}$ and which assumes a disconnected public, local communities in the Northern Cape were immersed in the issue of asbestos. Community residents accepted the scientific approach as valid and participated in various ways, supporting scientists' attempts to systematically measure the distribution of ARDs or to clean-up waste asbestos products in the areas of health and mining rehabilitation. Their participation through collective community action led to broadened, hybrid understandings of risk which incorporated both scientific and community perspectives 


\section{Medical screening: measuring the extent of ARDs \\ Numerous scientific studies, undertaken since the} 1920s, have documented the links between asbestos and the diseases referred to above. During the 1950s, pioneering South African medical assessments linked asbestos to mesothelioma. As, however, the asbestos industry, operating in conjunction with the apartheid government, increasingly funded and controlled South African medical research into ARDs, there was a dearth of research publications in the 1960s and 1970s (McCulloch 2002, 2005). A resurgence of research occurred in the 1980s when anti-apartheid trade unions sought to address occupational health issues (Braun et al. 2003) and in the 1990s when they sought alliances with the new democratic government. At the same time, civil society organisations, such as the CPAA, emerged and challenged the compensation system for ARDs. ${ }^{9}$

Although the classification of ARDs, the degree of illness and the appropriateness of compensation has seldom been value-free and 'objective' (see Waldman 2005), the underlying political and economic issues have generally been obscured. Furthermore, because the asbestos debate emphasises complex notions such as minute fibre size, threshold levels, diagnosis of various forms of ARD and so forth, it has marginalised lay people and ARD sufferers - many of whom in the Northern Cape are illiterate - from engaging in these aspects of the debate (cf. Leach et al. 2002).

Community residents did, however, support measures to scientifically evaluate risk. In the 1980s, the CPAA arranged for visiting scientists to collect data and measure asbestos pollution in Prieska. ${ }^{10}$ In 1996, the National Union of Mine Workers invited the Industrial Health Research Group, based at the University of Cape Town to 'review the occupational histories and audit the chest $x$-rays and lung functions' of asbestos mineworkers from Kuruman (IHRG 1996). In addition to producing medical evidence of the widespread presence of ARD, the research documented the deep anxiety felt by former mineworkers about the longterm risks to their health, inadequate health and safety, the lack of information about ARDs and the compensation system.

In May 1997, Dr Ahmon Randeree, a Canadian doctor aware of the Canadian litigations and working in the main Northern Cape hospital in Kimberley, administered a questionnaire to over 1,000 Prieska residents in order to identify people suffering from respiratory problems. The CPAA supported this research by helping residents to complete questionnaires, informing people when $x$-rays would be taken and when visiting doctors were doing assessments. CPAA organisers also compiled a databasis of all residents who were experiencing respiratory problems. Preliminary results suggested that 30 per cent of Prieska's residents were suffering from ARDs, but that only 5 per cent had experienced occupational exposure to asbestos (Asbestos Project Prieska [n.d.]). The Northern Cape Department of Health then appealed for help with the medical examinations. Professor Richards from the Gauteng Johannesburg Hospital responded and brought with him a team of specialists to examine patients. This study confirmed the preliminary results suggested by the CPAA and revealed 'a significant number of previously undiagnosed uncompensated cases' of ARD among Prieska's residents (Hopley and Richards [n.d.]: 1).

At a community level, there has been widespread support for 'scientific assessments' of the health risks and for medical research. There has also been some attempt, on the part of scientific institutions and personnel, to explain complicated scientific discourse and procedures to the lay public (cf. Michael 2002). Concerns with health, with the availability of health services and the polluted quality of Prieska's air dominated the scientific/medical surveys (Minutes of the Asbestos Forum Meeting, 6 November 1997). The assessments over the distribution of ARDs were both initiated and accepted by the CPAA, by provincial government officials and by locally involved community members. The multi-stakeholder forum thus provided a space in which community residents supported scientific processes and definitions, although this article later shows that the recognition of scientific/medical literature was more ambivalent. Within this multi-stakeholder forum, extensive debate also explored the dangers created by asbestos mining and how environmental rehabilitation should proceed.

\section{Environmental rehabilitation of mines, dumps} and mills

The South African Government has assumed responsibility for the rehabilitation of the abandoned asbestos mines and dumps and has initiated a reclamation process. Nonetheless, the costs associated with this are enormous and, in 1998, it was estimated that a further R50 million would still 
be needed (Venter 2005). As this estimation exceeds the funding available for rehabilitation, it poses serious problems for local government departments seeking to assist their rural constituencies.

Between 2002 and 2003, the Department of Minerals and Energy spent R17 million safeguarding the worst Northern Cape mines. ${ }^{11}$ In April 2004, the Department of Minerals and Energy (DME) reported that it had rehabilitated about 60 per cent - or '111 mines and 578 dumps' of South Africa's asbestos mines (Venter 2004). ${ }^{12}$ Yet only 45 per cent of the Northern Cape asbestos mines had been treated. In Prieska, the DME reported that rehabilitation, which involved reducing the dump size to an acceptable gradient, covering the polluted area with clean soil, establishing anti-erosion measures and planting vegetation, had decreased the presence of airborne asbestos fibre from 1 fibre $/ \mathrm{mm}$ to 0.01 fibre $/ \mathrm{mm}$. This has generally been considered an expensive, but ultimately the most practical, solution (Shabangu 2001).

The CPAA's campaigns to address asbestos pollution emphasised community participation and local development throughout. In most instances this entailed collaboration with scientists, rather than the development of local experts. Nonetheless EcoRehabilitation, a local company, won the tender to rehabilitate the Koegas mine dump. The owner, a Griquatown resident, employed workers from Prieska, Marydale and Griquatown in order to fulfil government requirements that this be a 'community initiative'. The work involved covering the dump with soil and constructing barriers to ensure that asbestos fibres would no longer contaminate the river. Several of the workers had parents who had been employed on the Koegas mine and all of them had relatives who had contracted ARDs. Eco-Rehabilitation's owner thus commented that the experience was one that 'touched' many of the workers as they realised that ARDs would no longer affect future generations. He himself felt the work to be 'close to my heart, with the knowledge that my ancestors lived at Koegas, and to now be physically involved at the place where they got sick and to be able to fully restore it with state support ...' This confidence that ARDs would no longer affect their children was contrasted with concern about asbestos exposure while working on site, although some safety measures were implemented. ${ }^{13}$ Although this provides a positive example of a community project with local beneficiaries, the manner in which workers were protected was influenced by sociocultural interpretations of risk. As discussed below, the workers' focus on visible fibres and the use of face masks may have offered partial protection against microscopic asbestos fibres, but is inadequate from a scientific/medical point of view.

The rehabilitation of mines and mine dumps is, however, only part of the problem. Because mining companies encouraged extensive, local use of its byproducts, asbestos waste has been found in many everyday contexts in Prieska. Not only is it cemented into the walls and roads, it is in the air - in sometimes visible and sometimes invisible, immeasurable quantities. It is this pervasive and general problem, discussed in the next section, which has provoked the most debate among affected communities.

\section{Compensation, community development and perceived risk}

It was common for asbestos waste products to be used in the construction of Northern Cape roads, buildings, temporary school classrooms, and roofs and ceilings (Venter 2004). The CPAA initially approached companies responsible for supplying asbestos-impregnated products, but without any success. Everite, for example, had supplied Prieska's asbestos cement roofs. When challenged about the inherent danger, Everite claimed that the roofs posed 'little or no additional health risk' (letter to CPAA, 21 June 1999). Everite's conclusion was based on the scientific evidence of an 'exceptionally low' count of between 1 and 3 fibres in an 8-hour sample and on 'international literature', which indicated that asbestos cement roofs did not enhance background levels of asbestos fibre. While this assessment follows conventional wisdom that asbestos-in-situ is best painted to minimise the release of fibres and left undisturbed, daily life does not allow for such clear-cut scenarios. The fact that roofs were broken in violent hailstorms or that people might drill holes to install new gutters and so forth were dismissed as insignificant in Everite's scientific calculation of risk.

In March 2000, the CPAA redirected their efforts to government and wrote to the Northern Cape Premier pointing out that there had been no risk assessments in towns where residents suffered from ARDs, such as Prieska, Maryvale, Griquatown, Boegoeberg, Niekerkshoop and Danielskuil (letter to 
the Premier, 20 March 2000). This resulted only in partial success. Although the government envisages replacing asbestos roofs and toilets 'where practically possible', to date, little has been done. In Prieska, it was 2003 before asbestos roofing and toilet sheets were finally replaced. Although done as a safety measure against future contraction of ARDs, some people remained in their houses while the roofs were being changed. As one asbestos sufferer commented 'what difference, [asbestos] is already in your lungs?' In other towns, people have little option but to continue to live in houses built with asbestos products and to take the chance that they and their families might, if they are not already sufferers, contract ARDs. In Griquatown, the CPAA representative campaigned to have the roofs changed, but found it difficult to pinpoint which government department should take responsibility. The Department of Health referred him to the Department of Housing, which in turn referred him back to Health. His experiences are indicative of the high costs involved in environmental rehabilitation, the widespread nature of the problem and the difficulty of persuading government officials, who recognise that asbestos pollution is a problem, that the roofs in a particular town are a priority for redress. In the case of Prieska, the overwhelming scientific evidence of the distribution of ARDs and in particular of mesothelioma, coupled with strong active community mobilisation, led to the replacement of asbestos roofs. Other smaller towns which do not have the same leverage with government departments, are not seen as being as dangerous and have less concerted community action.

The Prieska debates on health and the distribution of ARDs also highlighted the significance of evaluating airborne asbestos pollution. As was the case with the medical screening, there was widespread community support for assessing the presence of airborne asbestos fibres. This, however, was a discussion that took place on two distinct levels - at the level of community concern over the dangers of constant exposure and at the level of scientific expertise, modelling and equations. At community level, notions of harm and risk concerned visible asbestos fibre and the use of asbestos in construction and infrastructure. At the scientific level, risk was evaluated in terms of wind direction and predicted deposition, microscopic fibres, statistical probabilities and so forth. As pointed out by a health professional based in Prieska, the quality of sampling varied between studies as the seasonal Northern Cape winds affected results (Minutes of the Asbestos Forum Meeting, 6 November 1997). Also at issue has been the analysis of fibre characteristics and correlating these with corresponding degrees of danger, dispersal and risk. Scientific experts disagreed on whether field sites were necessary, on the value of anecdotal evidence and on the accuracy of modelling dispersion patterns (letters from the Institute for Ecological Rehabilitation, 18 June 1999).

In contrast, community residents focused on visible fibres. In Prieska, concerns were frequently voiced: after a cloudburst several streets 'were exposed to asbestos' (through erosion caused by strong rain); during the seasonal heavy winds people were able to pick up fibres (notes from the Meeting of the Asbestos Working Group, 24 February 1998); construction work often disturbed asbestos deposits and workers refused to continue until the asbestos had been dealt with (letter from Town Clerk, 9 January 1986). Even sites that had ostensibly been treated were not secure. For example, visits to the rehabilitated Prieska mill revealed asbestos fibre lying exposed on the topsoil. Although resonating with the 'scientific establishments' debates on fibre deposition and risk, these community concerns about visible fibres were not seriously addressed despite community involvement in the Asbestos Working Group. Instead they were seen as background to the 'more serious' questions of medical screening and environmental rehabilitation and, although minuted in the asbestos forum meetings, did not result in direct action. As suggested by the Prieska mill example, just enough was done to allay people's fears and this primarily involved covering visible asbestos fibre. Where covering the fibre was not possible, such as the case of construction workers exposing asbestos, only material in the immediate vicinity of proposed work has been removed. In other Northern Cape towns, in which the CPAA had a weaker presence and where mobilisation around asbestos issues was not as strong, people did not respond to heavy rains, violent wind storms or construction work with concerns about visible asbestos fibres. This reflects how, in Prieska, people's understanding of risk and their scientific knowledge has been enhanced through action and collective participation.

The backgrounding of community concerns with visible fibres and with their living conditions has thus occurred in tandem with the emphasising of medical 
screening and environmental rehabilitation and is illustrative of the widespread and continued faith in science as a means to deal bureaucratically with disease and problems. Ultimately, however, the rehabilitation of mines, the medical assessments of ARD and of rates of infection, and the limited attempts to address community concerns have not improved the daily experiences of most Northern Cape residents. In the following section, residents' informal assessments of risk are evaluated, with attention paid to their understandings of the harm posed by asbestos and to their corresponding ways of coping.

\section{Death in the context of asbestos}

Stephens (2002) and Fischer (2005) point out that, in contrast to expert assessments of risk, lay people approach scientific predictions of risk from a sociocultural perspective. Public concern with risk is thus neither irrational nor based on scientific misunderstanding; but is a vital component of human subjectivity and identity (Lupton 1999; Wynne 1995). Michael's concept of 'apprehension' - a process by which lay people 'assess the status of sources of knowledge' and tie these assessments to local identity and culture - shows how people recast and broaden scientific/medical risk in terms of moral judgements and emotional responses (Michael 2002: 367). In a process of 'apprehension', and in contrast to what was discussed in the official Asbestos Working Group meetings, informally the people of Prieska and Griquatown emphasised their experiences of damaged bodies, their family relationships and their dependency on ARD compensatory payments for survival. They thus interpreted harm in terms of emotions, bodily integrity and financial responsibility or, to paraphrase Michael (2002: 373), they encountered knowledge through their bodies. Such a perspective offsets the medical and technical ways of describing 'risk' by relocating danger in terms of personal experiences and social relations. For these towns' residents, what is of concern is not the risks that isolated individuals face, but the wider networks of social relationships and how these are simultaneously threatened by ARDs and sustained through government disability grants and ARD compensation payments.

While scientific discussion on ARDs has focused on individuals, the Northern Cape is an area where extended families experience widespread and pervasive death from ARDs. It is common for families to watch, and try to assist, many members suffering and dying from ARDs. Emily Julies, for example, witnessed her husband, son, father-in-law and both brothers-in-law dying from ARDs. Half her husband's extended family (21 out of 34 people) had contracted ARDs, with men and women being equally affected. The widespread presence of asbestos is thus a collective disaster. A Department of Health, Welfare and Environmental Affairs survey (n.d.) revealed that 43 per cent of respondents had ARD sufferers in their family, while 60 per cent of respondents had watched a family member die from ARD (n.d.: 2). Ideas about death thus pervade people's experience of ARDs. The following selection of quotes comes from Northern Cape ARD patients, whose experiences have been poignantly portrayed in Hein du Plessis's photographic exhibit:

I've worked at this hospital for 21 years and l've seen many, many people die from asbestos dust. When you see them gasping for breath you think: 'Lord, what will my hour be like?'

(Anne van Staden, 51, asbestosis patient and hospital employee)

I was 12 when I started helping my parents work asbestos at Koegas. Now asbestos will be my end. For the past 23 years l've worked at the hospital and l've seen many people end up in the mortuary. Little did I know that I would also end up here because of asbestos. My father died in 1993 because of the dust and my mother is also suffering because of it. We are five children and three of us also have it.

(Audrey van Schalkwyk, 54, asbestosis patient and mortuary employee)

The asbestos is eating me up and it is taking me to my grave. We are dying here.

(Willem Olyn, 63, asbestosis patient)

I'm ready to die. But there are 15 people depending on my pension and when I die they will have no income.

(Jan van Staden, 70, asbestosis patient)

The pervasive association of asbestos with ideas about death suggests that an exclusive focus on scientific and technological innovation may not lead to radical improvements in people's lives. Although the actions called for by the CPAA - the rehabilitation of houses, streets, mills and the 
removal of other sources of asbestos pollution should create healthier environments and should reduce people's exposure to risk as defined in the scientific sense, community understandings of risk are not necessarily predicated on probability or future anxiety. Instead, they are often informed by past experiences, combined with social relations and personal emotions. Indeed, as Michael (2002: 362) has argued, people's understanding of science and medicine is intricately interwoven with local cultural dynamics and identities. Wynne's interpretationist approach similarly focuses on understanding scientific knowledge in terms of faith, trustworthiness, credibility and social relationships (Wynne 1995). It is about understanding how the public experience, interpret and relate to scientific knowledge, about how they assess different claims to knowledge and link these claims to other aspects of their social identity. The following section explores how people cope - and live with - ARDs and asbestos pollution. In so doing, this article argues for an understanding of risk that is socially and culturally contextualised. It suggests alternative ways in which people conceptualise the dangers and risks; ways which are not revealed in processes of formal participation, but which inform their coping strategies and which may, ironically, increase their exposure to risk.

\section{Living with asbestos pollution and perceived risk}

According to the doctor, I've lived in Prieska too long.

(Bettie Jacobs, 75, mesothelioma patient)

In Griquatown and Prieska, people's emic interpretations of their exposure to asbestos are sometimes aligned to, but at other times, contradictory to medical and scientific interpretations. Nonetheless, emic understandings of the risks of exposure provide ways of situating danger and of developing locally 'appropriate' responses to these hazards. In so doing, they create possibilities for residents to practise 'good health' and to continue to live in these towns. In contrast to medical assessments and scientific discourses of future probability and exposure to harm, Griquatown residents were most concerned with occupational exposure acquired 20-30 years ago during their employment on asbestos mines and with environmental exposure sustained when they were young (when their parents worked on the mines). Even so, Prieska residents acknowledged that the possibility of ARD contraction remained high, despite rehabilitation. Although suggestions have been put forward to shut down Prieska and relocate the people, residents did not take these suggestions seriously. They have chosen, somewhat paradoxically, to remain in the town. Many people born here were emphatic that they would rather die of ARDs than leave Prieska. As a local school teacher commented: 'It's their place, this. People are buried here, they grew up here'. Dolf Beukes, an ARD sufferer, explained his attachment to the town as follows: 'I have grown roots here, I was brought up here, born here. It is where my parents were. When I opened my eyes, I was here. I can travel anywhere, but I will always return here. I love this place'.

Similarly Griquatown residents have returned home after contracting ARDs. As explained by one patient:

When I was completely sick, then I came home because I was born here. And all of us ... my father is buried here, my mother is buried here, my one brother is [buried] here as well, also from the dust because he also worked on Blouboskuil.

This meant that, on the one hand, ideas about harm and risk were firmly couched in the historical context of mining irresponsibility and callousness towards town residents. As one person commented 'it is a shame that Cape plc treats our people like this'. On the other hand, these conditions were mitigated by families' historical continuity and ongoing networks of relationships through which ARD sufferers find solace and respite. As suggested above, people affected by ARDs used their pensions to provide for relatives beyond their nuclear families and people turned to their extended kin for support. Families in the Northern Cape towns were connected through their long-term residence in the town, through complicated relationships of consanguinity and affinity which were hard to untangle and trace, through the practice of having voorkinders, ${ }^{14}$ through extending kinship to people who participated in intimate activities such as childbirth and ritual, ${ }^{15}$ and through common experiences of poverty and oppression. It was family members who helped out in times of need, who shared food and clothes with other family members, who drew people into networks of responsibility and obligation and, in so doing, emphasised individuals' value while providing support and solidarity. Prieska residents were characterised as 'caring for each other', as 'helping 
each other', and as 'being patient with one another'. It was these sentiments that made people feel that they were 'happy', despite knowing that they had been exposed and were likely to contract ARDs. Indeed as Cobb (1976), Dressler (1980) and Kleinman (1995) have argued, social support provides a valuable aid in terms of coping with disease and stress.

Although, as suggested earlier, most people accepted the scientific interpretations of $A R D$, there was considerable disagreement over how serious different forms of ARD were (Waldman 2005). ARDs are difficult to pin down, both medically and socially. One of the primary areas of disagreement concerns diagnosis and degree of severity of the disease. Mossman and Gee (1989), in their review of ARDs, categorise four types of benign disorders stemming from asbestos exposure, namely pleural effusion or fluid on the lungs, pleural plaques, pleural fibrosis and rounded atelectasis. These disorders do not generally produce pain but sufferers do experience shortness of breath and some discomfort. Three serious and debilitating forms of disease have also been linked to asbestos, namely lung cancer, asbestosis and mesothelioma. Asbestosis and lung cancer are primarily occupational hazards as contracting these diseases is linked to exposure rates. Mesothelioma (a malignant cancer) is unrelated to dosage and trivial exposure can lead to cancer of the abdominal cavity or lung lining. The fact that exposure is followed by an extended latency period (of up to 40 years) before diagnosis and that the condition is untreatable heightens the dangers.

In South Africa, people who suffer from ARDs are eligible to receive a state pension if they have more than 40 per cent damage to their lungs (or what is known as 'second degree' illness in South Africa). This provides a small but steady monthly income. In addition, former employees of the mines are able to receive compensation from the government-run Medical Bureau of Occupational Diseases (MBOD). The MBOD pays compensation for asbestosis, mesothelioma and lung cancer (Myers 1981: 241) and distinguishes between 'first degree' asbestosis or pleural plaque (it used these terms somewhat interchangeably) and 'second degree' infection (which could comprise asbestos infection plus additional damage to the lungs, either from tuberculosis or smoking). The apparent similarity between the definitions of asbestosis and pleural plaque raised, for many sufferers, questions about medical definitions and legal compensation. People understood that 'second degree' referred to the increased severity of mynstof although medically the various forms of ARD are constructed as different kinds of diseases, rather than as variations in degrees of severity. Pleural plaques are billed as benign and inert and are therefore not seen as being related to other, more severe forms of ARD or to lead to further damage of the lungs. Asbestos sufferers do not however draw a distinction between pleural plaques and other forms of asbestos disease. They do not accept that other asbestos-related complications are not related to the presence of plaques. Their experience of ARDs stresses the interrelated nature of these diseases.

People's emic understandings of ARD emphasised the destructiveness of all forms of the disease and they scorned the medical classification of some ARDs as benign or debilitating. From the residents' perspectives, all ARD patients suffered from the physical deterioration of their lungs, and as the following quotes indicate, degrees of seriousness could be conceptualised in terms of 'holes' or absence:

I did not even [consider removing my husband's lungs] because there were no lungs. You see, my husband's lungs looked like that cloth you see there ... you cannot see anything there ... now its just tendons and [remnants] of the lung that are there, because the asbestos has worked its way through. He looked like that crocheted cloth, there ... he looked like a sieve.

(Emily Julies, Griquatown)

I feel like an empty shell that does not have lungs or a heart inside it. Just the other day I commented that it feels as though one of my lungs is already 'light', that's how it feels inside.

(Lena Lucas, Prieska)

The lungs dry out. One day I assisted when they did an autopsy. His lungs were so finished that only the oesophagus remained. There were no lungs, they were disintegrated.

(Audrey van Schalkwyk, Prieska)

Thus, in contrast with the medical, scientific view put forward in Asbestos Working Group meetings, which argued that certain forms of ARD were more severe and debilitating than others, emic definitions focused instead on ill-health and on people's ability 
to 'feel' complete. Asbestos was seen to affect not only people's lungs, but to pervade their bodies and their wellbeing. As one CPAA campaigner described it:

Asbestos settles in people's stomachs. And then those people swell up. You think they have TB [tuberculosis] or some type of cancer and they become thin. Because their stomachs are full of water ... its asbestos lodged in the stomachs.

Medical practitioners working in the Northern Cape saw this as part of a 'gross elaboration' of the dangers of asbestos. They argued that the Northern Cape residents blamed all ill-health on asbestos, but actually tuberculosis and smoking had far greater impacts on their wellbeing. ${ }^{16}$ Nonetheless, in doctors' experiences, so pervasive was the tendency to see asbestos as the cause of ill-health that 'people get very upset when they're told they don't have asbestosis'. In providing their own interpretations of what happened to their lungs and how asbestos fibres affected their bodies, the Northern Cape residents were able to redefine risk and to shape their daily experiences in ways that were understood to provide a degree of safety.

The dangers of inhaling asbestos dust and fibre were readily accepted, although as demonstrated above, visible fibres provoked community action and outrage and were seen to be fatal. This contradicts scientific evidence which posits that once-off exposure to microscopic fibres can lead to mesothelioma. As one CPAA organiser expressed it, 'Asbestos is not dangerous if it's not visible'. Because of this emphasis on visible fibres, people were willing to work on the rehabilitation of mine dumps wearing only face masks. Similarly, Prieska residents watched their asbestos roofs being removed and cleaned up the mess without requesting protection. In addition, women who had given birth to children were particularly careful about their exposure to asbestos. They believed that cancer of the womb was caused by the necessity of using 'bush toilets' and argued that the wind blew the fibre into their vaginas and their underwear then kept this fibre in place.

These emic beliefs were overly reliant on the presence of visible asbestos fibres and did not stress the dangers of invisible, microscopic fibres.

Nonetheless, this position enabled people to continue to live in these rural towns and to cope with their experiences. As Dressler (1980) has argued, cultural factors can serve a 'beneficial or protective function', in that they 'aid individuals in their personal adaptations.' Even though these adaptations may not interpret risks from a scientific/medical perspective, they reduced stress and provide ways to continue living in polluted environments.

\section{Conclusion}

The interpretation of risk thus occurs at many levels which are, at times, disparate and contradictory such as disagreement between medical experts and community residents about the severity of different ARDs or the condition of people's lungs - but which can also be complementary - such as the importance of documenting the extent of ARDs in Prieska and the desire to deal with environmental pollution. Scientific interpretations of risk and public understandings of risk are not mutually exclusive. In arguing that ARDs are only caused by visible fibres, residents create a 'safe zone' in which to live. They do not oppose scientific evidence - indeed much of this is widely accepted and supported - yet the information is absorbed and adapted in ways that makes everyday life possible, although ironically does not provide protection from invisible and microscopic asbestos fibres. Although these emic understandings are thus susceptible to scientists and medical experts' claims that most people do not understand the complexity of scientific debates (Flynn 1999) and that they will 'live with' rather than 'die from' benign ARDs, ultimately neither medical/scientific understandings of risk - and the actions taken to minimise this - nor emic interpretations of harm and bodily experience - and residents' attempts to live in asbestos-polluted environments - can prevent some people from contracting ARDs. Both the scientific and the emic models have limitations and the 'safe zones' created in both these models do not actually constitute safety for the residents of Griquatown and Prieska. As illustrated in this study of asbestos pollution, local understandings of risk and harm reflect a messy process of convergence and divergence, in which risk and harm are interpreted through the lenses of personal bodily experience and social relationships of dependence. Nonetheless, it is through opportunities for participation and collective action that these perspectives become more closely connected and undergo a process of adaptation, of broadening that brings together the two seemingly disparate conceptualisations of risk. 
Yet, as Michael has recently argued, the relationship between science and sociocultural values is 'discontinuous, fractured and non-linear'. Moreover the intersection between these two domains is 'uncertain and contingent' (2002: 370-3). This allows for an accommodation of medical and scientific discourse in the official arena of local governance processes which encourage community participation and for the cultural interpretation of scientific knowledge. However, there are also implications beyond how people participate in policy and in debates that are centred on scientific issues. Although scientific and local knowledge may coexist and intertwine, as is evident in this article, the formal processes of participation were framed around medical expertise and knowledge. Despite official representation on the Asbestos Working Group, at no stage did any community residents or CPAA organisers point to possible disjunctures between

\section{Notes}

* This research has been funded by the ESRC Science in Society Programme. The opinions expressed here do not necessarily reflect those of the funding institution. I am grateful to everyone who contributed towards this research, especially the residents of Griquatown and Prieska and for the constructive criticisms received from Fiona Ross, by anonymous readers and by the editors of the IDS Bulletin.

1 Namely pleural effusion (or fluid on the lungs), pleural plaques, pleural fibrosis and rounded atelectasis which are seen to cause some breathlessness and discomfort and lung cancer, asbestosis and mesothelioma which are serious and debilitating (Mossman and Gee 1989).

2 Emic refers to people's own interpretations or to behaviour explained in terms meaningful to the actor.

3 Although prospecting for asbestos was done in these other towns, it was never found in sufficient quantities to warrant large-scale corporate mining. Nonetheless, numerous people migrated to Prieska to work on the mines.

4 The International Labour Organisation ratified the 'Safety in the Use of Asbestos' convention in 1986 which sought to protect workers and others exposed to it. From the mid-1980s, increasing numbers of European countries banned the mining, production, sale, use and import or export of asbestos (London Hazards Centre n.d.). By the scientific and informal beliefs about ARDs. Was this because local understandings were not perceived of as knowledge? Was it because official procedures through the very process of being formal - define emic understandings and local contextual knowledge as irrelevant? Was it because highly specialised, professional knowledge limited local people's participation possibilities to the realm of supporting scientists? Certainly all of these factors occurred in the case described here. As Leach et al. (2002) argue, providing local people with a 'voice' can take place within very restricted frameworks. If local people are to participate more fully in policy processes and debates about science, risk and technological hazard scientific, medical interpretations have to be correlated with local, situated knowledges. Failure to do so ultimately limits the efficacy of both sets of knowledge - of medical science and of emic values to protect communities from further risk.

end of 2005 all European Union countries should have banned asbestos (Castleman 2001).

5 Trade Union Advisory Committee to the OECD. 30/05/2005. (Draft) OHSE Sust/Dev Country Profiles for Asbestos, www.global-unions.org/ pdf/ohsewpL_6.EN.pdf (accessed 16 June 2005).

6 During the apartheid era, the largest Northern Cape asbestos mines were Koegas, Elandsfontein and Blackridge (Hall 1930). These mines closed in the late 1970s because they were worked out or in the 1980s when it become impossible to ignore the associated dangers.

7 Including the Departments of Environmental Affairs, Health, Social Security and Welfare, Minerals and Energy, Water Affairs, Housing, Labour and Nature Conservation.

8 The traditional approach to Public Understanding of Science (PUS) assumes that scientific literacy is a positive attribute which assists people in being 'better citizens' (Michael 2002: 359).

9 The Medical Bureau of Occupational Diseases (MBOD) has compensated mine employees for ARD since 1956 (McCulloch 2002). For Northern Cape residents, securing MBOD compensation was a bureaucratic nightmare. They had to travel to medical examinations, complete detailed questionnaires and negotiate with the MBOD based more than $600 \mathrm{~km}$ away. The lack of access to transport facilities, to telephones, to their own medical records (often held by doctors in neighbouring towns) and to money, coupled with 
high levels of illiteracy, made this an extremely difficult undertaking.

10 Although the first study of ARDs (since the early 1960s) was conducted in Prieska in the late 1980s (Reid et al. 1990), this focused on elite white residents and excluded the CPAA's constituency. Nonetheless, the research found high mesothelioma and mortality rates for both men and women. As white women were never employed on asbestos mines, this highlighted the high levels of environmental exposure.

11 South African Government, www.info.gov.za/ aboutsa/minerals. htm (accessed 16 June 2005). The Asbestos Working Group, an informal national grouping of concerned people, noted in February 1998 that there were no inventories of rehabilitated and unrehabilitated mine dumps (letter to the Premier, 20 March 2000). This resulted in the production of an 'Asbestos Rehabilitation Priority Index Database'.

12 Some 90 per cent of the asbestos mines in the Limpopo area, 60 per cent of the mines in the

\section{References}

Asbestos Project Prieska (n.d.), unpublished document

Balshem, M. (1991) 'Cancer, Control, and Causality: Talking About Cancer in a Working-Class Community', American Ethnologist 18.1: 152-72

Braun, L.; Greene, A.; Kisting, S.; Jacobs, N.; Manseu, M. and Singhal, R. (2003) 'Scientific Controversy and Asbestos: Making Disease Invisible', International Journal of Occupational and Environmental Health 9: 194-205

Castleman, B. (2001) 'Controversies at International Organizations over Asbestos Industry Influence', International Journal of Health Services 31.1: 193-202

Cobb, S. (1976) 'Social Support as a Moderator of Life Stress', Psychosomatic Medicine 38: 300-14

Coombs, A. (2002) 'Three Minerals, Three Epidemics', paper presented in Australia, November 2002, www.johnpickering.co.uk/news/three-minerals.html (accessed 9 August 2004)

Cornwall, A. (2004) 'New Democratic Spaces: The Politics and Dynamics of Institutionalised Participation', IDS Bulletin 35.2: 1-10

Department of Health, Welfare and Environmental Affairs (n.d.) 'Preliminary Results Asbestos Study', unpublished document, Prieska

Distrikstrekordboek (1978) Scrapbook compiled by successive Griquatown Magistrates, unpublished
North West and 21 per cent of mines in Mpumalanga, were rehabilitated.

13 Workers were warned of the dangers, screened for diseases before beginning work and after completion, and provided with safety masks.

14 Children born to young mothers who were neither married nor in serious, long-term relationships.

15 For example, a woman who helped deliver babies would become the child's 'grandmother' and would assume responsibilities in relation to this.

16 Community rejection of the link between disease (particularly cancer) and lifestyles is not uncommon. Balshem documents how communities living in 'cancer hot spots' refute medical notions of causality, arguing instead that cancer is something everyone is born with and that it can be activated by random acts of fate, rather than controlled through healthy lifestyles (Balshem 1991).

Douglas, M. and Wildavsky, A.B. (1983) Risk and Culture: An Essay on the Selection of Technical and Environmental Dangers, Berkeley: University of California Press

Dressler, W.W. (1980) 'Coping Dispositions, Social Supports, and Health Status', Ethnos 8.2: 146-71

Ehrlich, R.I.; Felix, M.A. and Leger, J.P. (1994) 'Three Minerals, Three Epidemics - Asbestos Mining and Disease in South Africa', in M.A. Melman and A. Upton (eds), Advances in Modern Environmental Toxicology: The Identification and Control of Environmental and Occupational Diseases: Asbestos and Cancer, Princetown: Princetown Scientific Publishing

Fairhead, J. and Leach, M. (2003) Science, Society and Power: Environmental Knowledge and Policy in West Africa and the Caribbean, Cambridge: Cambridge University Press

Felix, M.A. (1991) 'Risking their Lives in Ignorance: The Story of an Asbestos-Polluted Community', in J. Cock and E. Koch (eds), Going Green: People, Politics and the Environment in South Africa, Oxford: Oxford University Press

Fischer, F. (2005) 'Are Scientists Irrational? Risk Assessment in Practical Reason', in Leach, M.; Scoones, I. and Wynne, B. (eds) Science and Citizens: Globalization and the Challenge of Engagement, London: Zed Books 
Flynn, T.G. (1999) 'The Two Cultures: Forty Years Later', in A.M. Herzberg and I. Krupka (eds), Statistics, Science and Public Policy IV. The Two Cultures? Proceedings of the Conference on Statistics, Science and Public Policy held at Hertmonceux Castle, Hailsham, UK, 21-24 April 1999

Furedi, F. (2002) Culture of Fear: Risk-Taking and the Morality of Low Expectation, London: Continuum

Gaventa, J. (2002) 'Introduction: Exploring Citizenship, Participation and Accountability', IDS Bulletin 33.2: 1-11

Hall, A.L. (1930) Asbestos in the Union of South Africa. Geological Survey Memoir No. 12, Pretoria: Department of Mines and Industries

Hessel, P.A. and Sluis-Cremer, G.K. (1989) 'X-ray Findings, Lung Function, and Respiratory Symptoms in Black South African Vermiculite Workers', American Journal of Industrial Medicine 15.1: 21-9

Hopley, M.J. and Richards, G.A. (n.d.) 'Asbestosrelated Disease, A Community-Based Survey and a Capture-Recapture Analysis', unpublished report

IHRG (1996) 'Report on the Audit of the AsbestosRelated Disease Surveillance Programme at GEFCO Crocidolite Asbestos Mine Conducted on 20 and 21 May 1996', unpublished report, Industrial Health Research Group

Kleinman, A. (1995) Writing at the Margin: Discourse Between Anthropology and Medicine, Berkeley: University of California Press

Leach, M.; Thompson, L. and Scoones, I. (2002) 'Citizenship, Science and Risk: Conceptualising Relationships across Issues and Settings', IDS Bulletin 33.2: 40-8

London Hazards Centre (n.d.) Asbestos London Hazards Centre, Interchange Studios, Dalby Street, London NW5 3NQ, UK

Lupton, D. (1999) Risk, New York: Routledge

McCulloch, J. (2005) 'Asbestos, Lies and the State: Occupational Disease and South African Science', African Studies 62.2: 2001-216

McCulloch, J. (2002) Asbestos Blues: Labour, Capital, Physicians and the State in South Africa, Oxford: James Curry

Meeran, R. (2003) 'Cape Plc: South African Mineworkers' Quest for Justice', International Journal of Occupational and Environmental Health 9.3: 218-29

Michael, M. (2002) 'Comprehension, Apprehension, Prehension: Heterogeneity and the Public Understanding of Science', Science, Technology and Human Values 27.3: 357-78
Mossman, B.T. and Gee, B.L. (1989) 'Asbestos-Related Diseases', New England Journal of Medicine 320: 1721-30

Myers, J. (1981) 'The Social Context of Occupational Disease: Asbestos and South Africa', International Journal of Health Services 11.2: 227-45

Newell, P. (2001) 'Managing Multinationals: The Governance of Investment of the Environment', Journal of International Development 13: 907-19

Randeree, A. (1998) 'Asbestos Pollution: What Needs to be Done', unpublished report by the Department of Environmental Affairs, Developmental Social Welfare and Health, South Africa

Reid, G.; Kielkowski, D. and Steyn, S.D. (1990) 'Mortality of an Asbestos-exposed Birth Cohort: A Pilot Study', South African Medical Journal 78: 584-7

Richards, P. (2006) 'Against Discursive Participation: Authority and Performance in African Rural Technology Development', paper presented at the EASST conference in Lausanne (Switzerland) in August 2006

Richards, P. (1989) 'Agriculture as Performance', in R. Chambers, A. Pacey and L.A. Thrupp (eds), Farmer First: Farmer Innovation and Agricultural Research, London: Intermediate Technology Publications

Shabangu, S. (2001) Budget Vote Speech by Deputy Minister of Minerals and Energy, National Assembly 8 May 2001, www.info.gov.za/speeches/2001/ 0105101045a1002.htm (accessed 14 May 2005)

Stephens, S. (2002) 'Bounding Uncertainty: The PostChernobyl Culture of Radiation Protection Experts', in S.M. Hoffman and A. Oliver-Smith (eds), Catastrophe and Culture: The Anthropology of Disaster, Oxford: James Currey

Venter, I. (2005) 'Still 50 Asbestos Sites To Rehabilitate', Mining Weekly Online, 15 July, www.miningweekly.co.za/article.php?a_id=70332 (accessed 24 August 2007)

Venter, I. (2004) 'SA Makes Progress in Asbestos-mine Rehabilitation', Creamer Media's Mining Weekly online, www.miningweekly.co.za/min/sector/ $\mathrm{coal} /$ ?show=54117 (accessed 29 April 2005)

Waldman, L. (2005) When Social Movements Bypass the Poor: Asbestos Pollution, International Litigation and Griqua Cultural Identity, IDS Working Paper 246: $1-40$

Ward, H. (2002) 'Corporate Accountability in Search of a Treaty: Some Insights from Foreign Direct Liability', Royal Institute of International Affairs Briefing Paper 4: 1-11 
Williams, J.J. (2004) 'Citizenship, Community Participation and Social Change: The Case of Area Coordinating Teams in Cape Town, South Africa', IDS Bulletin 35.2: 19-25

Wynne, B. (1996) 'May the Sheep Safely Graze? A Reflexive View of the Expert-Lay Knowledge Divide', in S. Lash, B. Szerszynski and B. Wynne (eds), Risk, Environment and Modernity: Towards a New Ecology, London: Sage

Wynne, B. (1995) 'The Public Understanding of Science', in S. Jasanoff, G.E. Markle, J.C. Peterson and T. Pinch (eds), Handbook of Science and Technology Studies, California: Sage Publications, Thousand Oaks: 361-88 